\title{
O processo de gramaticalização do verbo IR no português
}

\author{
brasileiro: um estudo diacrônico
}

\begin{abstract}
Alcione Gonçalves*
Resumo: Esta pesquisa, em uma perspectiva diacrônica, verifica o estágio do processo de gramaticalização do verbo IR no português brasileiro. Para a realização deste trabalho, partimos do quadro teórico proposto por Hopper \& Traugott (1993) e Heine et al. (1991) sobre a gramaticalização, assim como a metodologia desenvolvida por Vianna (2000) e Vitral (2006), buscando depreender o estatuto morfossintático desse verbo. A proposta metodológica consiste nos cálculos de frequência que funcionam como um mecanismo capaz de comparar $\mathrm{o}$ comportamento de determinados elementos em funções gramaticais e lexicais, ou seja, a análise da frequência de um item, em suas funções, sejam elas lexicais, sejam elas gramaticais, permitindo-nos identificar, quantativamente, processos de gramaticalização. Para a formação do corpus, seguimos uma metodologia que privilegia textos de gêneros similares entre os séculos XVIII, XX e XXI. Nosso intuito é, portanto, determinar em que estágios da língua, sejam eles anteriores, sejam contemporâneos, as perífrases verbais, formadas com verbo IR, tornaram-se mais frequentes, retomando a questão da instabilidade da formação do futuro, constatando que a língua é um mecanismo auto-regulador, constituindo-se em um processo contínuo e ininterrupto.
\end{abstract}

Palavras-chave: verbo IR; gramaticalização; Forma lexical; Forma gramatical; Diacronia.

\begin{abstract}
This research, in a diachronic perspective, verifies the process of grammaticalization of the verb TO GO in Brazilian Portuguese. For this research, we based the theoretical framework on Hopper \& Traugott (1993) and Heine et al. (1991) who refers to grammaticalization, as well as on the methodology developed by Vianna (2000) and Vitral (2006), searching for the morphosyntactic status of that verb. The methodology consists of frequency calculations that work as a mechanism to compare the behavior of certain elements in grammatical and lexical functions, i.e., the frequency analysis of an item in its functions, whether lexical, whether grammatical, allowing us to identify, quantitatively, processes of grammaticalization. For the formation of the corpus, we followed a methodology which focuses on texts of similar genres between the XVIII, XX and XXI centuries. Our aim is therefore to determine at what stages of the language, whether past, whether contemporary, the periphrases, formed with the verb TO GO, became more frequent, returning to the issue of instability in the formation of future tense, noting that language is a self-regulating mechanism, thus becoming a continuous and uninterrupted process.
\end{abstract}

Keywords: Verb TO GO; Grammaticalization; Lexical form; Grammatical form; Diachrony.

\section{O Conceito de Gramaticalização}

\footnotetext{
* Mestre em Linguística pela Pontifícia Universidade Católica de Minas Gerais (PUC - Minas), Professora do Departamento de Linguagem e Tecnologia (DELTEC) do Centro Federal de Educação Tecnológica de Minas Gerais (CEFET-MG).
} 
Dentre o universo das mudanças e variações linguísticas, encontra-se um subconjunto de variações que descreve como um item lexical vem a desempenhar funções gramaticais ou um item gramatical vem a assumir funções mais gramaticais ainda. Este fenômeno é denominado Gramaticalização ${ }^{1}$.

Ressaltamos que há muitas dificuldades em se definir o termo gramaticalização, tendo em vista a multiplicidade de estudos acerca deste tema. Muitas definições foram abordadas e vários autores, dentre eles Meillet (1912), Lehmann (1982), Hopper \& Traugott (1993), Heine et al. (1991) e Bybee et. al. (1991), trataram da questão da gramaticalização.

Para Castilho (2010, p. 982), o termo refere-se ao "trânsito de uma forma livre, menos gramatical, para uma forma ligada, mais gramatical”. Para Kurylowicz (1965, p.32), a gramaticalização refere-se à "passagem gradual de um morfema de uma categoria lexical para uma categoria gramatical ou de um 'status' menos gramatical para um plano mais gramatical." Martelotta et al. (1996), assim como Heine et al. (1991), postulam que a gramaticalização não se refere propriamente a uma teoria da linguagem, mas a uma teoria de desenvolvimento das formas gramaticais. $\mathrm{O}$ que esses autores defendem é que a gramaticalização é um tipo de mudança linguística, assim como a mudança fonética e a lexicalização. Para Hopper \& Traugott (1993, p. 1), a gramaticalização é definida como um processo em que "tanto itens lexicais e construções formam-se em certos contextos linguísticos para exercer funções gramaticais quanto itens gramaticais desenvolvem novas funções gramaticais." Tal definição aponta para a dinamicidade das línguas, uma vez que trata de formas já gramaticalizadas e que se tornam mais gramaticalizadas ainda.

Adotaremos o conceito de gramaticalização, de acordo com Heine et al. (1991), para designar um processo unidirecional, linear, em que itens lexicais passam a assumir funções gramaticais e, uma vez gramaticalizados, continuam a desenvolver novas funções gramaticais, tendendo a se tornarem mais regulares e mais previsíveis, uma vez

\footnotetext{
1 Alguns autores utilizam o termo Gramaticização (Hopper, 1991; Givón, 1995; Matisoff, 1991) sem muitas diferenças significativas como substitutivo para Gramaticalização. O primeiro termo é normalmente empregado para se referir a um processo sincrônico, enquanto o segundo se refere a um processo diacrônico. De modo inapropriado, também podem aparecer como sinônimos de gramaticalização os termos reanálise, sintaticização, desbotamento (bleaching) semântico, condensação, redução etc. Esses termos são vistos como inapropriados uma vez que permitem identificar apenas características de natureza sintática e/ou semântica. (Heine et al., 1991, p. 3)
} 
que esse processo transporta o elemento do nível da criatividade momentânea do discurso para as restrições da gramática. O processo de gramaticalização é, portanto, irrecorrente, interminável e sempre ativo. Dessa forma, uma construção analítica, por exemplo, pode gramaticalizar-se em uma construção sintética, que pode ser preterida em relação a outra construção analítica, que se gramaticaliza e, assim, sucessivamente.

\section{Motivação para a mudança}

Vários são os motivos que podem levar uma palavra a gramaticalizar-se. Esta motivação, segundo Neves (1997, p.130), pode estar "tanto nas necessidades comunicativas não satisfeitas pelas formas existentes", quanto "na existência de conteúdos cognitivos para os quais não existem designações linguísticas adequadas", devendo-se observar que "novas formas podem desenvolver-se a despeito da existência de estruturas velhas, funcionalmente equivalentes". A gramaticalização está diretamente relacionada à noção de que toda gramática é capaz de fornecer vários mecanismos de codificação para as funções da linguagem que os falantes mais utilizam. (NEVES, 1997)

Assim como Meillet (1912), Hopper \& Traugott (1993) defendem que a gramaticalização se dá pela busca constante de expressividade. Esta mudança, segundo os autores, está fundamentada em estratégias cognitivo-pragmáticas utilizadas pelos falantes. Para isso, os usuários da língua lançam mão de duas estratégias: a primeira é a rotinização, que se caracteriza pela repetição das expressões, resultando na simplificação da fala e na economia de esforços mentais; e a segunda é a expressividade, caracterizada pelo uso de formas inovadoras para retratar algo já conhecido e, consequentemente, favorecendo o fortalecimento da informatividade.

Segundo Bally (1952), é a necessidade de comunicação, que ele chama de "expressividade na linguagem", que motiva as mudanças linguísticas. Sob duas tendências opostas, essas mudanças se dão de forma coletiva e inconsciente. A primeira tendência é a expressiva que enriquece a linguagem por meio de elementos novos, provenientes da afetividade e da subjetividade, formando a linguagem corrente do dia-a-dia. A segunda é a tendência intelectual que elimina os aspectos do pensamento que são obscuros e estranhos, dando origem à linguagem científica. Para o autor, é a tendência expressiva a de maior força na atuação de mudança do sistema linguístico, uma vez que as necessidades da vida se mostram mais determinantes. 
Para Bybee et al. (1991), no entanto, as necessidades comunicativas não parecem ser motivo plausível para a motivação da mudança. Para eles, é pouco provável que haja um conjunto intercultural de necessidades que as línguas precisam cumprir. Novas formas podem surgir no processo de gramaticalização mesmo já havendo formas disponíveis na língua para a mesma função.

Embora saibamos que há divergências entre os autores a despeito das motivações que levam um item a se gramaticalizar, não podemos negar a relevância das necessidades expressivas na efetivação dos processos de gramaticalização, assim como não podemos negar que circunstâncias de ordem linguística, histórica e social favorecem essas mudanças.

Vale ressaltar que a motivação para a gramaticalização encontra-se nas necessidades comunicativas não satisfeitas pelas formas já existentes, assim como na existência de conteúdos cognitivos para os quais não há designações linguísticas adequadas.

\section{Gramaticalização: um estudo diacrônico ou sincrônico?}

Embora a gramaticalização possa ser percebida em recortes sincrônicos da língua, ela é um processo predominantemente diacrônico. Estudos empreendidos por Meillet (1912), Sapir (1921), Kurylowicz (1965) e Benveniste (1989) também trataram os processos de gramaticalização sob uma perspectiva diacrônica.

Givón (1995) postula que o processo de gramaticalização pode ser visto tanto diacronicamente quanto sincronicamente. Para ele, uma construção linguística pode desenvolver-se gradualmente no tempo, passando por estágios diversos até chegar a uma gramaticalização plena, resultando em um processo diacrônico. Do ponto de vista cognitivo, a gramaticalização é um processo instantâneo, envolvendo um ato mental pelo qual uma relação de similaridade é reconhecida, ou seja, um item lexical, em determinado contexto, pode ter um uso gramatical. Assim, teremos um processo sincrônico.

Assim como Givón, Hopper \& Traugott (1993) postulam que os estudos empreendidos acerca da gramaticalização podem ser observados tanto sob uma perspectiva diacrônica quanto sincrônica. Em uma perspectiva sincrônica, a gramaticalização é entendida como um fenômeno morfossintático discursivo. Em português, por exemplo, temos as formas verbais de futuro sintético que convivem com as formas do futuro perifrástico, ou seja, há mais de uma possibilidade para expressar a mesma categoria gramatical, comprovando, desta forma, a dinamicidade dos usos linguísticos. Por uma perspectiva diacrônica, podemos observar em que 
estágios da língua itens lexicais tornaram-se gramaticais e quais itens gramaticais tornaram-se mais gramaticais ainda.

Martelotta et al. (1996, p.27) defendem que, sob o ponto de vista histórico, os processos de gramaticalização de um item podem dar a impressão de "uma sequência de mudanças ocorridas no tempo" e, sob uma perspectiva sincrônica, é possível observar "um conjunto de polissemias coexistindo."

Segundo Neves (1997), a questão acerca de a gramaticalização constituir-se em um processo diacrônico ou sincrônico liga-se ao caráter "gradual" versus "instantâneo". Do ponto de vista histórico, o processo é gradual, e do ponto de vista da construção, instantâneo. Para a autora, embora possa ocorrer uma estrutura substituindo outra, em determinado momento, ambas as formas, a velha e a nova, coexistirão. Essa variação não é nada mais do que o reflexo do caráter gradual da mudança linguística.

Para Gonçalves et al. (2007, p. 16), a gramaticalização pode ser vista tanto sob a perspectiva sincrônica quanto diacrônica. Para os autores, será diacrônica se "a preocupação do estudo estiver voltada para a explicação de como as formas gramaticais surgem e se desenvolvem na língua" e será sincrônica se o enfoque for a "identificação de graus de gramaticalidade que uma forma linguística desenvolve a partir dos deslizamentos funcionais a ela conferidos pelos padrões fluidos de uso da língua, portanto, sob um enfoque discursivopragmático."

Em uma concepção funcionalista, a gramaticalização constitui-se em um processo essencialmente diacrônico, uma vez que se trata de mudança linguística. Deve-se esclarecer, no entanto, que nem toda mudança linguística se constitui em um caso de gramaticalização. Variações de natureza fonológica como /ei/ em peixe - "pexe", feira - "fera" não se constituem a um processo de gramaticalização, visto que não há alteração gramatical.

Os processos de gramaticalização, portanto, podem ser observados tanto de um ponto de vista sincrônico quanto diacrônico.

\section{Descrição dos critérios metodológicos adotados}

\subsection{Caracterização dos corpora}

Para a realização desta pesquisa, seguimos uma metodologia que privilegie textos de gêneros similares entre os séculos XVIII, XX e XXI. Foram selecionados textos de quatro gêneros em uso no período contemporâneo da língua portuguesa, 
séculos XX e XXI, e quatro gêneros, funcionalmente semelhantes, referentes ao período moderno, segunda metade do século XVIII. ${ }^{2}$

Embora saibamos que não se observa uma equivalência absoluta entre gêneros semelhantes de sincronias distintas, apresentamos, como corpus, quatro duplas de gêneros funcionalmente equivalentes: (I) Cartas Pessoais dos séculos XVIII e XX; (II) Cartas de Comércio do século XVIII e E-mails Comerciais do século XXI; (III) Artigos Científicos do século XVIII e do século XX e (IV) Cartas-denúncia do século XVIII e Denúncias do século XX.

A escolha desses gêneros textuais baseou-se nos estudos empreendidos por Lobato (2009) acerca da necessidade de rigor na seleção de textos que constituirão os corpora para estudos diacrônicos, especificamente, para os estudos acerca de processos de Gramaticalização. Para o desenvolvimento de uma metodologia, a autora aponta para a necessidade de um corpus que inclua gêneros variados e funcionalmente equivalentes em diferentes períodos da língua.

Segundo Lobato,

quando se pesquisa gramaticalização (ou outro processo de mudança linguística), considera-se mais eficiente que se busquem amostras do maior número possível de formas de desempenho linguístico de cada época contemplada no estudo. Certamente, havendo maior variedade de gêneros, existem mais possibilidades de ambientes semânticos evidenciadores do processo. Além disso, quanto mais gêneros são utilizados em uma pesquisa, mais fiel é a imagem que se forma acerca da língua de um determinado período e, indiretamente, acerca das características sociais e culturais daquela época. (LOBATO, 2009, p., 11)

Portanto, a seleção desse corpus (Carta Pessoal, Denúncia, Artigo Científico e Carta de Comércio) deveu-se à comprovação de Lobato de que a escolha desses gêneros justifica-se uma vez que cada um traz características distintas de produção textual, estabelecendo relações discursivas entre seus interlocutores, apresentando-se, assim, de forma variada.

\footnotetext{
${ }^{2}$ Nosso objetivo, nesta pesquisa, não é estudar a escolha dos gêneros textuais para a formação de uma metodologia de pesquisa. Para aprofundar neste assunto, conferir LOBATO (2009).
} 
Sendo assim, o corpus do século XVIII ${ }^{3}$ é constituído de 21 cartas pessoais, 35 cartas de comércio, 02 artigos científicos e trechos da Devassa da Inconfidência Mineira, totalizando 32.967 palavras $^{4}$.

Para completar o corpus, foram selecionadas 15 cartas pessoais, 90 e-mails comerciais, 03 artigos científicos e 21 denúncias de crimes diversos, representativas do período contemporâneo, séculos XX e XXI, totalizando 33.349 palavras. Nota-se que o número total de palavras dos textos selecionados, tanto no período moderno quanto no contemporâneo, equipara-se. Cada gênero apresentou uma variação de palavras de 7.500 a 8.500 , como mostram os quadros 01 e 02 .

As 21 cartas pessoais ${ }^{5}$ do século XVIII pertencem ao Arquivo Público Mineiro (APM) e correspondem ao período de 1770 a 1790. Essas cartas constam das coleções da Família Joaquina Bernarda e da Família Cordeiro Valadares, ambas de Pompéu (Minas Gerais), totalizando 7.529 palavras.

As 15 cartas pessoais do período contemporâneo foram escritas por belohorizontinos entre as décadas de 1950 a 1970. Essas cartas retratam experiências de familiares durante viagens a estudo e a passeio e são pertencentes ao acervo pessoal da Família Camisassa Rodrigues. Essas cartas totalizam 7.789 palavras.

As cartas pessoais deste período apresentam um alto grau de familiaridade entre os interlocutores, uma vez que se trata de correspondência entre membros de um mesmo núcleo familiar, ou seja, entre pais, filhos e irmãos. Esse alto grau de intimidade pode ser observado por meio da escolha do léxico, das expressões coloquiais e de recursos de oralidade, como mostra o excerto abaixo:

(1) Puxa, até que enfim as madames se dignaram a responder as cartas (essa gente aí sou eu só, porque o resto da patota é composta de um bando de relapsos [...]. Ainda não

\footnotetext{
${ }^{3}$ Para uma investigação de textos de sincronias passadas, Barbosa (1999) propõe a pesquisa de textos em três esferas de circulação desses textos, a saber: a esfera pública, que inclui documentos oficiais da administração pública; a esfera privada com textos redigidos por comerciantes, religiosos, pessoas jurídicas, representando, assim, determinada instituição e a particular que se refere à esfera doméstica em que se encontram textos destinados a familiares e amigos.

${ }_{4}^{4}$ Para garantir o equilíbrio dos cálculos, na análise de frequência, procurou-se manter quantidades aproximadas de palavras de cada amostra de gênero textual.

${ }^{5}$ Segundo Pessoa (2002 apud Lobato, 2009), a escrita de cartas entre amigos e familiares tornou-se mais comum a partir do século XVIII, entretanto, somente a partir da segunda metade do século XIX e começo do século XX, este gênero, carta pessoal, fixou seus moldes, revelando uma linguagem mais próxima do cotidiano.
} 
comecei a trabalhar. Já disse isso em outra carta. E já tou de sacola cheia, com neurose de à toa e tudo [...]. Aqui tá chovendo tanto, só vendo. Tá daquele jeito (é com jota, viu, Nilda?), sabe Naka, que faz sol bonito a semana inteirinha, chovendo horrores só à noite, faltando luz e tudo e, no fim-de-semana, é água pura. Neca de hípica pra menina aqui, que tá ardendo pra se queimar um pouquinho, que tá descorada que nem calça Lee. (Carta Pessoal 01, Período Contemporâneo, grifos nossos)

As 35 cartas de comércio, escritas no século XVIII, foram selecionadas entre as várias transcritas e editadas por Barbosa (1999). Essas cartas foram produzidas no período de 1793 a 1798 e foram escritas nos estados da Bahia, Rio de Janeiro e Pernambuco, totalizando 8.674 palavras.

As cartas de comércio, retiradas da pesquisa de Barbosa (1999), encontram-se na Biblioteca Nacional de Lisboa: Seção de Reservados (BNL). Segundo o autor, elas foram escritas por portugueses que viviam no Brasil e enviadas à Metrópole, mais especificamente a Antônio Esteves Costa, rico comerciante português radicado no Brasil.

Os 90 e-mails comerciais, referentes ao período contemporâneo, equiparam-se às cartas de comércio do período moderno. Todos os e-mails foram produzidos por funcionários de empresas estabelecidas na capital mineira. Esses e-mails totalizaram 8.446 palavras. A linguagem observada nos e-mails comerciais é de cunho mais formal, uma vez que a troca de mensagens se dá entre interlocutores que não se conhecem ou se conhecem pouco. Os excertos 02 e 03 dão-nos um claro exemplo de como se estabelece a linguagem entre os interlocutores nos e-mails comerciais:

(02) Prezado $\mathrm{NP}^{6}$,

encaminho, em anexo, o orçamento solicitado.

Qualquer dúvida, entre em contato.

Aguardo retorno.

Atenciosamente, NP. (E-mail Comercial 19, Período Contemporâneo)

(03) Prezado cliente,

Estamos muito felizes em poder atendê-lo.

\footnotetext{
${ }^{6}$ Nome Próprio
} 
O NP é um absorvedor UVA que utiliza partículas microfinas, que agem como micropigmento e absorvedor. Filtro solar altamente eficiente devido à sua tripla ação: absorvedor UV, dispersor e refletor da luz. Devido a essa ação de reflexão da luz é que o NP possa (sic) ser classificado como físico, pois o que diferencia ou classifica os tipos de filtros solares é o processo de proteção do filtro. Como o NP apresenta essa tripla ação, a propriedade de reflexão de luz pode conferir a ele essa característica de fotoproteção física. Por gentileza, poderia nos informar em qual trabalho foi publicado para que possamos avaliar a informação publicada. A NP agradece seu e-mail e lhe deseja uma boa tarde. (E-mail Comercial 32, Período Contemporâneo)

Vale ressaltar que o gênero e-mail comercial apresenta características distintas das cartas de comércio do período moderno, embora apresentem funções semelhantes. Nos e-mails comerciais, encontramos textos de curta extensão, sucintos e diretos, cujo objetivo principal centra-se na dinamicidade da comunicação.

Quanto ao período contemporâneo, foram analisadas 21 denúncias de crimes diversos, coletadas na Secretaria do Tribunal de Justiça de Minas Gerais, totalizando 8.650 palavras. Essas denúncias correspondem ao período de 1999 a 2008, abrangendo Comarcas tanto da capital quanto do interior de Minas Gerais.

Equivalentes às denúncias do período contemporâneo, serão analisados trechos da Devassa da Inconfidência Mineira. Dentre esses trechos, encontram-se o "Auto de corpo de delito", parte introdutória, a "Portaria do Governador Visconde de Barbacena" e 6 Cartas-denúncia, perfazendo um total de 7.796 palavras.

A Devassa era o nome dado a um processo judicial, de natureza criminal, estabelecido nas Ordenações do Reino. Ao contrário dos processos criminais instaurados, hoje, por intermédio de Ministérios Públicos, o indiciado, na época do estabelecimento da coroa portuguesa no Brasil, não tinha nenhum direito à defesa. Uma vez instaurado o processo, havia regras bem claras já estabelecidas e a sentença final era sempre dada por um juiz ou pelo tribunal. 
Tendo em vista que a Inconfidência Mineira $^{7}$ foi o primeiro movimento separatista a manifestar com clareza a intenção da colônia de romper suas relações com a metrópole, foram instauradas duas Devassas, a saber, uma em Ouro Preto e outra no estado do Rio de Janeiro. A Devassa de Minas foi enviada ao Rio de Janeiro e anexada a esta. Vale lembar que este processo vigorou no Brasil até a promulgação do Código Criminal do Império. Grande parte dos volumes dos Autos da Devassa da Inconfidência Mineira encontram-se sob a guarda da Biblioteca Nacional (BN-RJ) no Rio de Janeiro.

Assim como nos e-mails comerciais, encontramos nas denúncias, referentes ao período contemporâneo, um conteúdo mais objetivo e impessoal do que se verifica nas cartas-denúncia, pesquisadas na Devassa da Inconfidência Mineira. Os textos jurídicos, referentes ao período contemporâneo, cumprem de forma mais direta o papel sociocomunicativo de acionar a autoridade judiciária, a fim que sejam tomadas as medidas cabíveis para cada denúncia efetivada pelo Ministério Público.

O quarto e último gênero textual, selecionado para compor esta pesquisa, é o artigo científico. Para o período moderno, século XVIII, foram coletados 02 artigos científicos. O primeiro intitulado "Memoria ${ }^{8}$ sobre a Plantação dos Algodões", de José de Sá Betencourt, e o segundo "Memoria sobre a Cultura da Urumbeba", de José Marianno da Conceição Velloso, datados de 1798 e 1799, respectivamente. Esses dois artigos totalizam 8.968 palavras.

Os artigos científicos do século XVIII são oferecidos ao Príncipe do Brasil, como mostrado no excerto abaixo:

\section{(4) SENHOR.}

Eu tenho a honra de apresentar a Vossa Alteza Real o breve resumo das minhas poucas observações sobre a plantação dos Algodões, sua exportação; e também das causas da decadência da lavoura de mandiocas no termo da Villa de Camamú....” José de Sá Betencourt.

7 A importância da Inconfidência Mineira reside no fato de este movimento exprimir a decadência da política colonial de Portugal e, ao mesmo tempo, de manifestar o desejo de liberdade da elite cultural do país, influenciada pelo movimento Iluminista francês e pela independência das 13 colônias inglesas na América do Norte que, apoiadas nas ideias iluministas, não só romperam com a metrópole, mas também criaram uma nação soberana, republicana e federativa.

${ }^{8}$ Lobato (2009) lembra-nos de que, no século XVIII, os textos não recebiam o rótulo de "Artigos Científicos" e, sim, de "Memorias". 
Para o período contemporâneo, foram selecionados $03 \operatorname{artigos}^{9}$ da área de Botânica, intitulados (I) "Manejo prático da Cochonilha Ortézia em pomares de citros"; (II) "Utilização de fungos entomopatogênicos para o controle de Orthesia praelonga" e (III) "Leprose dos citrus: biologia e diagnóstico do vírus". Esses artigos encontram-se publicados no periódico chamado Laranja (da cidade de Cordeirópolis, São Paulo) e totalizam 8.464 palavras.

Ao contrário dos textos científicos, produzidos no período moderno, as produções científicas contemporâneas respaldam-se na intertextualidade como instrumento para o embasamento teórico, a legitimação e a comprovação de hipóteses a serem investigadas, apresentando uma linguagem bastante simples e direta, com destaque para o léxico com características específicas da área, ou seja, de cunho técnico. Situação esta bastante distinta dos textos científicos produzidos no século XVIII em que há, muitas vezes, a visão impressionista e subjetiya do pesquisador, sendo predominantemente descritivos e expositivos.

Para melhor visualização do corpus selecionado, apresentamos, a seguir, os Quadros 01 e 02 com o detalhamento e a descrição dos textos.

QUADRO 1: Caracterização do Corpus - Período Moderno

\begin{tabular}{|c|c|c|c|c|c|}
\hline Código & Corpus & Descrição & Gênero & Datação & $\mathbf{N}^{0}$ Palavras \\
\hline $\mathbf{C P}$ & $\begin{array}{l}\text { Cartas } \\
\text { Pessoais }\end{array}$ & $\begin{array}{l}21 \text { cartas pertencentes ao } \\
\text { Arquivo Público Mineiro } \\
\text { (APM). }\end{array}$ & Carta & $\begin{array}{c}1770 \\
\mathrm{a} \\
1790\end{array}$ & 7.529 \\
\hline $\mathrm{CC}$ & $\begin{array}{l}\text { Cartas } \\
\text { de } \\
\text { Comércio }\end{array}$ & $\begin{array}{l}35 \text { cartas escritas nos estados da } \\
\text { Bahia, Rio de Janeiro e } \\
\text { Pernambuco. }\end{array}$ & Carta & $\begin{array}{c}1793 \\
\mathrm{a} \\
1798\end{array}$ & 8.674 \\
\hline
\end{tabular}

\footnotetext{
${ }^{9}$ Embora tenham sido selecionados 3 artigos científicos para o período contemporâneo e 2 artigos, referentes ao século XVIII, observamos que, nos artigos científicos do período contemporâneo, a contagem total de palavras se aproxima bastante, com 8.464, do número total de palavras dos artigos científicos do período moderno, com 8.968 .
} 


\begin{tabular}{|c|c|c|c|c|c|}
\hline $\mathbf{A C}$ & $\begin{array}{c}\text { Artigos } \\
\text { Científicos }\end{array}$ & $\begin{array}{l}\text { Artigo 1: "Memoria sobre a } \\
\text { plantação dos algodões", de } \\
\text { José Sá Betencourt. } \\
\text { Artigo 2: "Memoria sobre a } \\
\text { cultura da Urumbeba", de José } \\
\text { Marianno da Conceição } \\
\text { Velloso. }\end{array}$ & Artigo & $\begin{array}{c}1798 \\
\mathrm{e} \\
1799\end{array}$ & 8.968 \\
\hline CD & $\begin{array}{l}\text { Cartas- } \\
\text { denúncia }\end{array}$ & $\begin{array}{l}\text { Trechos da Devassa da } \\
\text { Inconfidência Mineira: "Auto } \\
\text { de corpo de delito", "Portaria } \\
\text { do Governador Visconde de } \\
\text { Barbacena" e } 6 \text { cartas-denúncia. }\end{array}$ & Carta & 1789 & 6 \\
\hline
\end{tabular}

QUADRO 2: Caracterização do Corpus - Período Contemporâneo

\begin{tabular}{|c|c|c|c|c|c|}
\hline Código & Corpus & Descrição & Gênero & Datação & $\mathrm{N}^{0}$ Palavras \\
\hline CP & $\begin{array}{c}\text { Cartas } \\
\text { Pessoais }\end{array}$ & $\begin{array}{l}15 \text { cartas pessoais escritas por } \\
\text { belo-horizontinos. }\end{array}$ & Carta & $\begin{array}{c}1950 \\
a \\
1970\end{array}$ & 7.789 \\
\hline EC & $\begin{array}{c}\text { E-mails } \\
\text { Comerciais }\end{array}$ & $\begin{array}{l}90 \text { e-mails comerciais escritos } \\
\text { por funcionários de empresas de } \\
\text { Belo Horizonte. }\end{array}$ & Carta & $\begin{array}{c}2002 \\
a \\
2008\end{array}$ & 8.446 \\
\hline $\mathbf{A C}$ & $\begin{array}{c}\text { Artigos } \\
\text { Científicos }\end{array}$ & $\begin{array}{l}\text { Artigo 1: "Manejo prático da } \\
\text { Cochonilha Ortézia em pomares } \\
\text { de citros". } \\
\text { Artigo 2: "Utilização de fungos } \\
\text { entomopatogênicos para o } \\
\text { controle de Orthesia } \\
\text { praelonga". } \\
\text { Artigo 3: "Leprose dos citrus: } \\
\text { biologia e diagnóstica do } \\
\text { vírus". }\end{array}$ & Artigo & $\begin{array}{c}2004 \\
\text { e } \\
2005\end{array}$ & 8.464 \\
\hline D & Denúncias & $\begin{array}{l}21 \text { denúncias de crimes } \\
\text { diversos, coletadas } \\
\text { Secretaria do Tribunal de } \\
\text { Justiça de Minas Gerais. }\end{array}$ & Carta & $\begin{array}{c}1999 \\
a \\
2008\end{array}$ & 8.650 \\
\hline
\end{tabular}


Verificando como se comportou a formação da perífrase verbal ir + Infinitivo, ao longo dos períodos moderno e contemporâneo, achamos pertinente analisarmos corpus de língua falada, a fim de permitir uma análise mais detalhada entre os usos dessa perífrase nas modalidades oral e escrita da língua. Como não existem registros de língua falada no século XVIII, foi possível selecionarmos apenas textos de língua oral do período contemporâneo, para isso selecionamos 09 entrevistas pertencentes ao Projeto Mineirês ${ }^{10}$, totalizando 34.497 palavras.

QUADRO 3: Caracterização do Corpus - Entrevistas

\begin{tabular}{|c|c|c|c|c|c|}
\hline Código & Corpus & "Descrição & Gênero & Datação & $\mathrm{N}^{\mathbf{0}}$ Palavras \\
\hline РМВН & $\begin{array}{c}\text { Transcrições } \\
\text { de Belo } \\
\text { Horizonte }\end{array}$ & Projeto Mineirês & Entrevista & 2006 & 34.497 \\
\hline
\end{tabular}

Uma vez feita a seleção dos gêneros textuais e a contagem de palavras em cada texto, nosso próximo passo foi identificar quais as ocorrências do verbo ir em cada texto de cada período. Para a análise da frequência de $i r$, foram registradas todas as ocorrências lexicais e gramaticais ${ }^{11}$ desse verbo em cada recorte temporal.

\section{Apresentação e discussão dos dados}

\subsection{Análise da frequência das formas lexicais e gramaticais do verbo ir}

Na tabela 1, apresentamos os dados, obtidos com a análise da frequência do verbo $i r$, na sua forma lexical e gramatical, referentes ao período moderno.

\footnotetext{
${ }^{10}$ O Projeto Mineirês - a Construção de um dialeto: o mineirês belo-horizontino - coordenado pela Prof ${ }^{\mathrm{a}}$ Jânia Ramos, é desenvolvido por pesquisadores da UFMG, visando ao estudo do dialeto falado em Belo Horizonte, contrapondo-o ao dialeto de dois dos mais antigos núcleos populacionais de Minas Gerais, Ouro Preto e Mariana. Dentre os objetivos deste projeto estão o de identificar e o de descrever as especificidades do dialeto belo-horizontino contemporâneo, buscando explicar essas especificidades com base em dados sociohistóricos por meio da realização de entrevistas sociolinguísticas, representativas do dialeto mineiro. (www.letras.ufmg.br/mineires)

${ }^{11}$ Como formas lexicais do verbo $\mathrm{ir}$, entendemos os usos do verbo em sua forma plena como vou, irei, fui etc. Para as formas gramaticais, entendemos os usos do verbo ir como auxiliar, seguido de um verbo principal no infinitivo, como em vou sair, vou trabalhar etc.
} 
TABELA 1: Frequência do verbo ir nos textos escritos - Período Moderno

\begin{tabular}{|c|c|c|c|c|c|c|c|}
\hline \multirow[t]{2}{*}{ Texto } & \multirow[t]{2}{*}{$\begin{array}{l}\text { Total de } \\
\text { palavras } \\
\text { por texto }\end{array}$} & $\begin{array}{l}\text { Formas } \\
\text { lexicais }\end{array}$ & & $\begin{array}{c}\text { Formas } \\
\text { gramaticais }\end{array}$ & & \multirow[t]{2}{*}{$\begin{array}{c}\text { Total da } \\
\text { frequência das } \\
\text { formas } \\
\text { Ocorrência }\end{array}$} & \\
\hline & & Ocorrência & $\%$ & Ocorrência & $\%$ & & \\
\hline$\overline{\mathrm{CD}}$ & 7.796 & 16 & 72.73 & 06 & 27.27 & 22 & \\
\hline $\mathrm{CC}$ & 8.674 & 37 & 94.87 & 02 & 5.13 & & \\
\hline $\mathrm{AC}$ & 8.968 & 03 & 50 & 03 & 50 & 06 & \\
\hline $\mathrm{CP}$ & 7.529 & 18 & 75 & 06 & & 24 & \\
\hline Total & 32.967 & 74 & 81.32 & 17 & 18.68 & 91 & \\
\hline Geral & & & & & & & 00 \\
\hline
\end{tabular}

$\mathrm{Na}$ análise da tabela 1, observamos que a frequência da forma lexical do verbo ir, 81.32 pontos percentuais, é significativamente maior do que a ocorrência do mesmo verbo na sua forma gramatical, com 18.68 pontos percentuais. Esses dados permitemnos inferir que, no século XVIII, é ainda predominante o uso das formas lexicais do verbo, o que não sinaliza, necessariamente, que o processo de gramaticalização de $i r$ não esteja em curso.

Estudos empreendidos por Coelho (2006, p.137) atestam que, já no período arcaico, a gramaticalização de ir não se encontrava em estágio inicial, o que sugere, segundo a autora, que o processo de gramaticalização desse verbo iniciou-se em período anterior, ou seja, quando era falado o galego-português, o romance ou mesmo o latim. Segundo Menon (2000, p.232), a gramaticalização de ir como auxiliar é muito antiga na língua. Encontramos, por exemplo, no Orto do Esposo, uma prova disso, pois ir ocorre como auxiliar de ir como mostra o excerto (5) abaixo.

(5) [...] e o seu primeiro filho he aquelle que esta e peccado e conpanhia de maaos, per que se uay hindo de mal e pior. E, como quer que elle esto vee, mais escolhe de sse queymar co fogo de peccado que se partir da maa companhia. (OE, p.351) (Grifos da autora) 
Estudando a trajetória do verbo ir, a partir de textos literários medievais, Lima (2001) atesta que as primeiras ocorrências de ir + infinitivo são encontradas no século XIII com valor de "tempo posterior", embora ainda não tivesse o valor real de tempo futuro, ou seja, a intenção de se projetar uma ação para ser realizada em um tempo futuro, como em (6). Segundo o autor, somente no século XIV, iniciou-se o processo de gramaticalização do verbo, em que ir é mais gramatical, funcionando, portanto, como morfema temporal, como em (7).

(6) Levantou-s' a velida, /levantou-s alva/ e vai lavar camisas/ eno alto:/vai-las lavar alva. (Cantigas de amigo de D. Dinis, Século XIII) (Grifos do autor)

(7) E há em ella muytos ryos, dos quais o primeiro he o Ebro que vay entrar ê no mar terreno. (Crônica Geral de Espanha, Século XIV) (Grifos do autor)

Segundo Lima (2001), no caso específico para a gramaticalização de ir, há três "traços comunicativos" fundamentais: (i) os traços semânticos de movimento e (ii) intenção, veiculados pelo significado de $i r$, assim como (iii) o traço futuro, que pode ser inferido, pragmaticamente, a partir da presença simultânea de ir e da oração que exprime o objeto desta ação (no sentido da finalidade) no mesmo contexto.

(...) a história do futuro com ir, em português, pode ser encarada como o processo pelo qual a construção ir + infinitivo (...) sofre a demoção gradual dos dois traços semânticos até o seu desaparecimento, acompanhada de progressiva promoção do traço 'futuro' à categoria do traço semântico, o que leva a que, no português atual, seja possível encontrar apenas ir como auxiliar de futuro na construção ir + infinitivo. (LIMA, 2001, p. 125)

Segundo o autor (op.cit.), a gramaticalização de ir aponta para uma clara "modificação semântica”, de um lado, e, por outro, para o fenômeno sintático de reparentetização (rebracketing), o que significa que a construção inicial do tipo $\mathrm{X}+i r+$ [verbo infinitivo $+\ldots]$ toma a forma de $\mathrm{X}+[i r+$ verbo infinitivo $]$, na qual a construção ir + infinitivo não apresenta, ainda, coesão sintagmática (bondedness), uma vez que, 
entre a forma finita de ir e o verbo no infinitivo, podemos intercalar, com algumas restrições, elementos frásicos como os advérbios, os pronomes etc., como mostram os excertos $(8)$ e (9), referentes às duas sincronias estudadas.

(8) Por tanto hiremos sómente apontar as espécies, cujo conhecimento he mais interessante em razão da sua relação com a Conchonilha. (Artigo Científico 02, Período Moderno, grifos nossos)

(9) [...] a vacina é de graça no posto e os alunos não, não vão lá tomar [...]. (Entrevista 02, Período Contemporâneo, grifos nossos)

Na sequência da modificação semântica e da reparentetização, surge um terceiro fenômeno característico do processo de gramaticalização do verbo $i r$, a subjetivação. Esse fenômeno significa que, enquanto, no princípio do processo, o verbo ir remete para o movimento, no fim do processo, o mesmo verbo serve, semanticamente, para localizar o estado de coisas em um eixo temporal, em função do sujeito da enunciação. (Lima, 2001, p. 141)

Outros estudos, de natureza sincrônica, realizados acerca da gramaticalização do verbo ir (Almeida, 1980; Silva, 2002 e Fonseca, 2010), atestam que esse verbo sofreu um "esvaziamento de traços" do seu significado inicial de deslocamento, sendo recategorizado como verbo auxiliar, quando seguido de um verbo principal, exprimindo a noção de futuridade. Para Silva (2002), embora haja esvaziamento semântico do verbo, é o significado de movimento, remanescente em ir, que dá à perífrase verbal o valor de posterioridade. Ressaltamos que este valor de movimento, transmitido metaforicamente à forma mais gramaticalizada, é o de um movimento temporal, mais abstrato, portanto, do que o sentido de movimento espacial da forma fonte.

Retomando nossa análise, dentre os quatro gêneros textuais pesquisados, os artigos científicos (AC) são os únicos que apresentam equilíbrio entre os usos das formas lexicais e gramaticais, com 50 pontos percentuais para cada forma. Nos demais gêneros, cartas-denúncia (CD), cartas de comércio $(\mathrm{CC})$ e cartas pessoais $(\mathrm{CP})$, o uso das formas lexicais é superior ao das formas gramaticais. São as cartas de comércio (CC) as que apresentam um percentual mais significativo para o uso das formas 
lexicais, com $94.87 \%$ em comparação a $5.13 \%$ para as formas gramaticais. Para as cartas pessoais (CP), o percentual de uso das formas lexicais é também muito significativo com $75 \%$ em comparação aos $25 \%$ para os usos das formas gramaticais.

No levantamento de dados acerca do uso das formas lexicais e gramaticais do verbo $i r$, no período moderno, fica evidente que, em três dos quatro gêneros textuais pesquisados, é a forma lexical do verbo a que predomina nos usos dos textos escritos, exceto para os artigos científicos (AC), embora a representatividade da frequência das formas lexicais, nesse gênero, ainda seja bastante significativa.

Os excertos (10) e (11) ilustram as formas lexicais e gramaticais do verbo $\mathrm{ir}$, encontradas no período moderno.

(10) [...] cada hum anno emtrão neste Rio de Janeyro, oito, dez, e doze milhons, e para a Bahia vay muyto mas; a serteza desta rezam se pode lá aberiguar sabendo Vossa Maggestade o que vay nas frottas cada anno [...]. (Forma Lexical) (Carta de Comércio 05, Período Moderno, grifo nosso)

(11) Pela denuncia incluza, não pense Vossa Senhoria que em mim he huã total materialidade porque Com efeito, eu penso ser tudo hu'a asneiras mas unicamente vou a salvarme, emdata aVossa Senhoria assim como amim maderão, bem certo quese Vossa Senhoria não fizer dela Cazo algu' [...]. (Forma Gramatical) (Carta Pessoal 07, Período Moderno, grifos nossos)

$\mathrm{Na}$ tabela 2, apresentamos a análise das frequências lexicais e gramaticais do verbo ir no período contemporâneo.

TABELA 2: Frequência verbo ir nos textos escritos - Período Contemporâneo

\begin{tabular}{|c|c|c|c|c|c|c|}
\hline \multirow[t]{2}{*}{ Texto } & $\begin{array}{c}\text { Total } \\
\text { de } \\
\text { palavras }\end{array}$ & $\begin{array}{l}\text { Formas } \\
\text { lexicais }\end{array}$ & & $\begin{array}{c}\text { Formas } \\
\text { gramaticais }\end{array}$ & & $\begin{array}{c}\text { Total da } \\
\text { frequência das } \\
\text { formas }\end{array}$ \\
\hline & & Ocorrência & $\%$ & Ocorrência & $\%$ & Ocorrência \\
\hline $\mathrm{D}$ & 8.650 & -- & $\overline{---}$ & 01 & 100 & 01 \\
\hline
\end{tabular}




\begin{tabular}{lccccccc}
\hline EC & 8.446 & 02 & 18.18 & 09 & 81.82 & 11 & 00 \\
AC & 8.464 & --- & --- & --- & --- & -- & 00 \\
CP & 7.789 & 19 & 38 & 31 & 62 & 50 & 00 \\
Total & 33.349 & 21 & $\mathbf{3 3 . 8 7}$ & 41 & $\mathbf{6 6 . 1 3}$ & 62 & 00 \\
Geral & & & & & & 0 \\
\hline
\end{tabular}

Os dados da tabela 2 mostram-nos um quadro bastante distinto da tabela 1 . No período contemporâneo, ao contrário do moderno, há predominância de uso das formas gramaticais de $i r$, com $66.13 \%$ de frequência, e $33.87 \%$ para as formas lexicais. O gênero artigo científico $(\mathrm{AC})$ foi o único que não apresentou ocorrência de uso das formas lexicais e gramaticais. Nos demais gêneros, observamos a predominância de uso das formas gramaticais com $100 \%$ de frequência nas denúncias (D), $81.82 \%$ nos e-mails comerciais (EC) e 62\% nas cartas pessoais (CP). O que os números da tabela 2 nos mostram é que a frequência de $i r$, como marcador temporal (forma gramatical), é mais significativa do que ir como marcador espacial (forma lexical), ou seja, o verbo é empregado mais na função de auxiliar do que na função de verbo pleno, observando-se, portanto, a expansão dos usos gramaticais de $i r$. Embora a frequência de $i r$, no gênero artigo científico (AC), tenha sido nula, os dados encontrados, no período contemporâneo, permitiram-nos identificar o processo de expansão pelo qual o verbo vem passando. Acreditamos que a ausência de formas lexicais e gramaticais de $i r$, nos textos científicos, deveu-se às características do próprio gênero textual. Destacaram-se, nesse gênero, os usos dos verbos modais para marcar futuridade, principalmente com o verbo poder, seja na modalidade deôntica, para marcar ordem fraca/forte, seja na modalidade epistêmica, para exprimir possibilidade.

Os excertos (12) e (13) ilustram as formas lexicais e gramaticais de ir, encontradas nos textos escritos no período contemporâneo. 
(12) As coisas estão caminhando direitinho, apesar de todos os pesares. Domingo fui à hípica com a Larri, mas o besta do sol não quis aparecer. (Forma Lexical) (Carta Pessoal 03, Período Contemporâneo, grifo nosso)

(13) Na próxima edição, vamos publicar uma matéria mostrando um Raio-X do Grupo NP. Estou colhendo as seguintes informações [...]. (Forma Gramatical) (E-mail Comercial 55, Período Contemporâneo, grifos nossos)

\subsection{Análise da frequência das formas lexicais e gramaticais do verbo ir nos textos de língua oral}

Na tabela 3, apresentamos os dados relativos à frequência do verbo ir nos textos de língua oral (LO).

TABELA 3: Frequência do verbo ir nos textos de língua oral - Período Contemporâneo

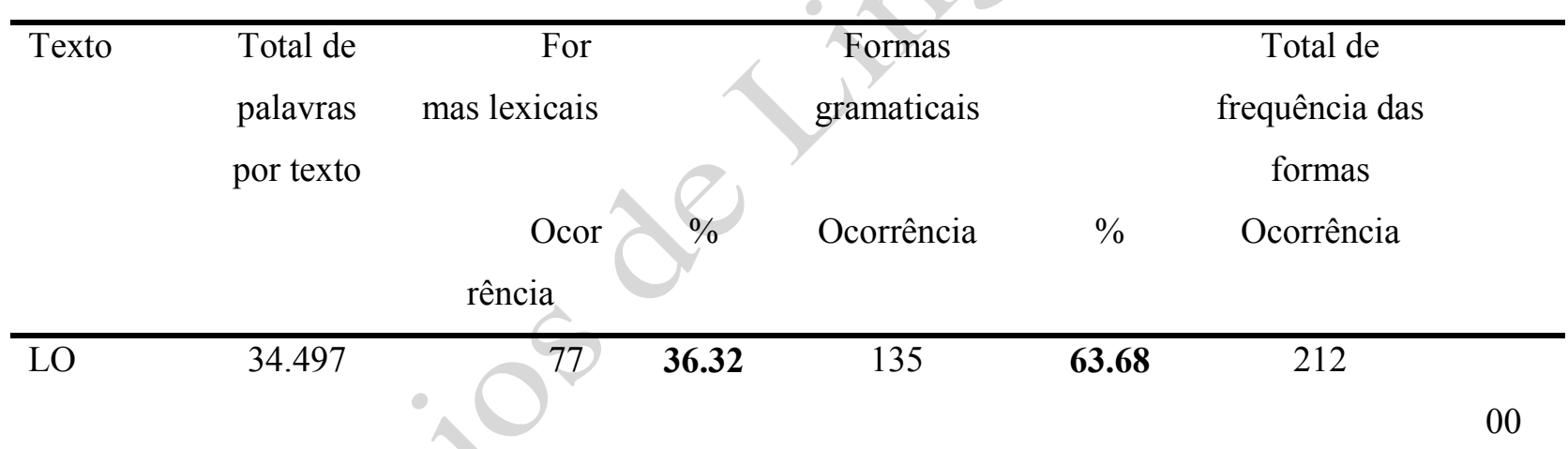

$\mathrm{Na}$ análise da tabela 3, verificamos que a frequência do verbo ir, nas formas gramaticais, é significativamente superior às formas lexicais, com $63.68 \%$ e $36.32 \%$, respectivamente. A análise dos dados, referentes aos textos de língua oral, reforça o que já foi constatado anteriormente, ou seja, há predominância de usos das formas gramaticais sobre as lexicais, evidenciando, quantativamente, que o processo de gramaticalização do verbo ir consolidou-se na língua. Esses dados permitem-nos deduzir, também, que o verbo ir é mais usado como auxiliar (marcador temporal) que como verbo pleno (marcador espacial). O que se evidencia, portanto, é o maior número 
de ocorrências desse verbo na formação de perífrases verbais como mostrado no excerto (15).

Os excertos (14) e (15) ilustram as formas lexicais e gramaticais do verbo $\mathrm{ir}$, encontradas nos textos orais no período contemporâneo.

(14) E aí depois dessa aula a gente vai pra casa né, é janta e assim, já morto de cansaço a única vontade que tem é de dormi [...]. (Entrevista 02, Período Contemporâneo, grifo nosso)

(15) [...] o psiquiatra vai ti dá um remedinho i ocê vai melhorá com isso i na verdadi num é isso essi remedinho vai ajudá mais i depois com'é qui fica cê tem qui tê um suporti cê tem qui tê um um um alicerci [...]. (Entrevista 01, Período Contemporâneo, grifos nossos)

Comparando os dados das tabelas 2 e 3, ou seja, os dados de Língua Escrita (LE), constituída pelos quatro gêneros textuais pesquisados no período contemporâneo, e os dados de Língua Oral (LO), referentes às entrevistas, teremos a tabela 4:

TABELA 4: Frequência do verbo ir nos textos escritos e orais - Período Contemporâneo

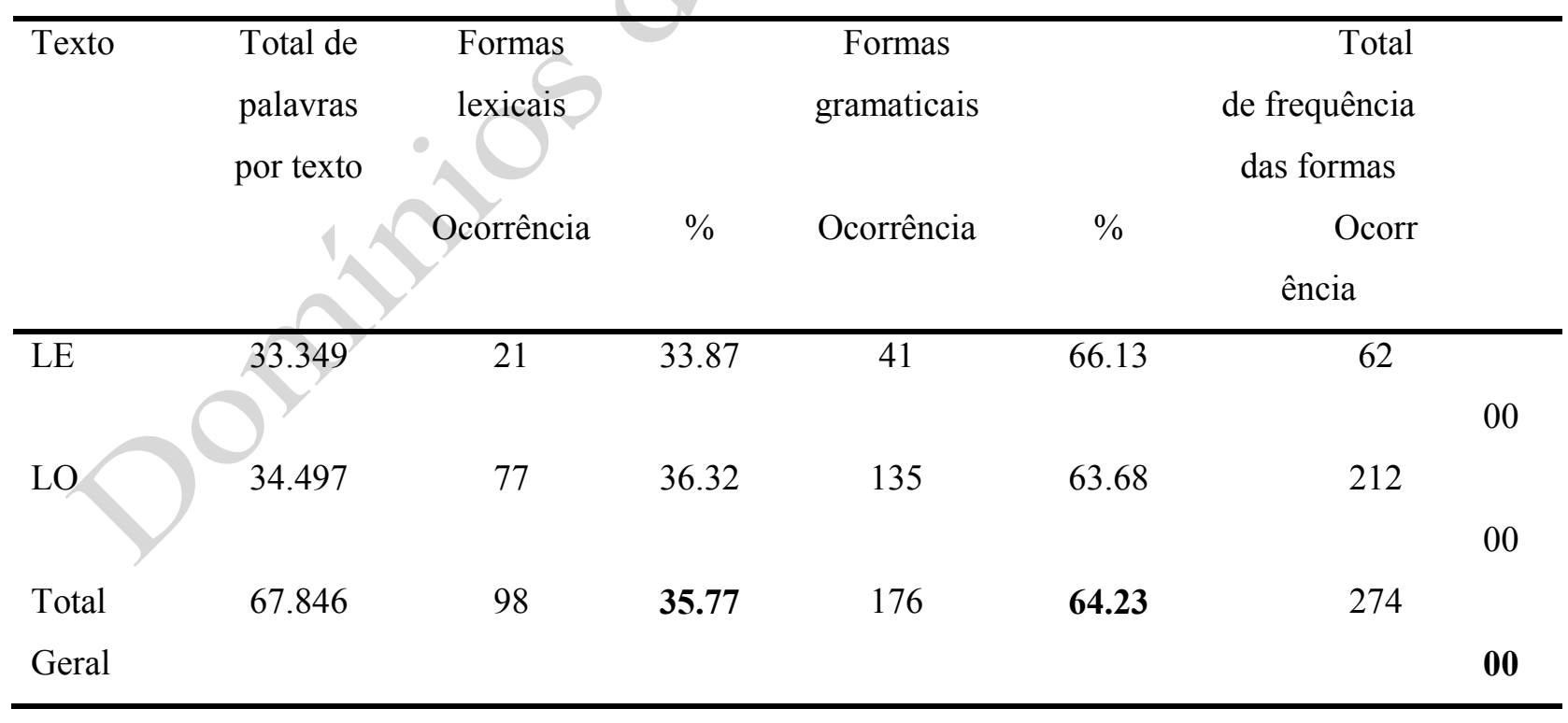

A comparação entre os dados, fornecidos pela tabela 4, permite-nos observar que, em ambas as modalidades de uso da língua, oral e escrita, há predominância de uso das formas gramaticais, com valores superiores a $50 \%$. Tais dados mostram-nos que, no 
período contemporâneo, os usos do verbo ir, como marcador temporal, consolidaram-se na língua. Ou seja, o quadro que encontramos é de um uso maior para as perífrases verbais, formadas pelo auxiliar $i r$, seguido de infinitivo.

Como pôde ser observado nos dados fornecidos pelas tabelas 1, 2 e 3, referentes aos períodos moderno e contemporâneo, tanto nas modalidades de língua escrita quanto oral, a gramaticalização de ir apresentou um comportamento regular e previsível, ou seja, houve ampliação dos usos das formas gramaticais em comparação aos usos das formas lexicais.

\subsection{Análise comparativa das frequências lexicais e gramaticais de ir}

Após efetuarmos a análise da frequência das formas lexicais e gramaticais do verbo $i r$, nos períodos moderno e contemporâneo, procedemos a um estudo comparativo dessas frequências, a fim de visualizarmos com maior precisão a evolução do processo de gramaticalização pelo qual o verbo ir submeteu-se e está sendo submetido.

A tabela 5 mostra-nos os dados relativos às frequências lexicais e gramaticais do verbo ir nos dois períodos pesquisados.

TABELA 5: Análise comparativa das frequências lexicais e gramaticais de ir por período e gênero textual

\begin{tabular}{|c|c|c|c|c|c|c|c|c|c|c|}
\hline \multirow{3}{*}{ PERÍODO } & \multicolumn{2}{|c|}{$\mathrm{CD} / \mathrm{D}$} & \multicolumn{2}{|c|}{$\mathrm{CC} / \mathrm{EC}$} & \multicolumn{2}{|l|}{$\mathrm{C}$} & \multicolumn{2}{|c|}{$\mathrm{CP}$} & \multicolumn{2}{|c|}{ Entrevistas } \\
\hline & $\mathrm{L}$ & G & $\mathrm{L}$ & G & $\mathrm{L}$ & G & $\mathrm{L}$ & G & $\mathrm{L}$ & G \\
\hline & $\%)$ & $\%)$ & $\%)$ & $\%)$ & $\%)$ & $\%)$ & $\%)$ & $\%)$ & $\%)$ & $\%)$ \\
\hline \multicolumn{11}{|l|}{ MODERNO } \\
\hline & 2.73 & 7.27 & 4.87 & .13 & 0 & 0 & 5 & 5 & -- & -- \\
\hline \multicolumn{11}{|l|}{ CONTEMPORÂNEO } \\
\hline & -- & 00 & 8.18 & 1.82 & -- & -- & 8 & 2 & 6.32 & 3.68 \\
\hline
\end{tabular}


A análise da tabela 5 permite-nos identificar que os dados obtidos nos corpora estão em conformidade com o que se espera na observação do processo de gramaticalização de um item, ou seja, a redução da frequência lexical do item e a, consequente, ampliação de sua frequência gramatical.

Nos gêneros textuais pesquisados, com exceção dos artigos científicos (AC), observamos um aumento significativo dos usos das formas gramaticais do verbo $\mathrm{ir}$, em comparação aos usos do mesmo verbo em sua forma lexical.

Os dados dos textos de língua oral evidenciam que o processo de gramaticalização do verbo ir já se consolidou na língua, mesmo antes do período moderno, século XVIII.

\section{Considerações finais}

Nesta pesquisa, tivemos por objetivo o estudo do processo de gramaticalização do verbo ir entre os períodos moderno e contemporâneo. A análise dos recortes temporais permitiu-nos deduzir que o processo de gramaticalização de $i r$ encontra-se em estágio adiantado no português brasileiro, sendo mais comum seu uso como marcador temporal, ou seja, como auxiliar em perífrases verbais, marcadoras de futuro, do que como marcador espacial, em sua forma lexical. O que se observou, portanto, foi uma redução significativa dos usos das formas lexicais que deram lugar às formas gramaticais, formadas pelo verbo ir, como auxiliar, seguido de um verbo principal no infinitivo.

A pesquisa, nos textos de modalidade oral, confirma a gramaticalização de $i r$, sendo amplamente utilizado na língua, em sua forma mais abstrata, assim como preveem os processos de gramaticalização.

Outra conclusão a que podemos chegar é que os dados, fornecidos pelas tabelas 1, 2 e 3 permitem-nos inferir que a forma perifrástica de futuro, formada por ir + infinitivo, vem, há bastante tempo, passando por variações, substituindo, gradualmente, as formas sintéticas para expressar futuro. 


\section{Referências bibliográficas}

ALMEIDA, J. Introdução ao estudo das perífrases verbais de infinitivo. São Paulo: Hucitec, 1980.

BALLY, C. Le langage et la vie. Genève: Droz, 1952.

BARBOSA, A. G. Para uma história do português colonial: aspectos linguísticos em cartas de comércio. 487 f. Tese (Doutorado), Faculdade de Letras, UFRJ. Rio de Janeiro, 1999.

BENVENISTE, E. A linguagem e a experiência humana. In: Problemas de Linguística Geral II. Tradução de Eduardo Guimarães et al., revisão técnica da tradução Eduardo Guimarães. $4^{\text {a }}$ ed. Campinas: Pontes, p. 68-80, 1989.

BYBEE, J.; PERKINS, R.; PAGLIUCA, W. The Evolution of Grammar: tense, aspect, and modality in the languages of the world. Chicago: University of Chicago Press, 1991.

CASTILHO, A. T. de. Nova gramática do português brasileiro. São Paulo: Contexto, 2010 .

COELHO, S. M. Estudo diacrônico do processo de expansão gramatical e lexical dos itens ter, haver, ser, estar e ir na língua portuguesa. $321 \mathrm{f}$. Tese (Doutorado), Faculdade de Letras, UFMG, Belo Horizonte, 2006.

FONSECA, A. M. H. da. A perífrase verbal ir + infinitivo e o futuro do dialeto Riopretano: um estudo na interface sociolinguística/gramaticalização. 174f. Dissertação (Mestrado) - Instituto de Biociências, Letras e Ciências Exatas, Universidade Estadual Paulista, São José do Rio Preto, 2010.

GIVÓN, T. Functionalism and Grammar. Amsterdam/Philadelphia: John Benjamins Publishing, 1995.

GONÇALVES, S. C. L. LIMA-HERNANDES, M. C. \& CASSEB-GALVÃO, V. C. (orgs.). Introdução à gramaticalização: princípios teóricos e aplicação. São Paulo: Parábola Editorial, 2007.

HEINE, B. et al. Grammaticalization: a conceptual framework. Chicago: University Chicago Press, 1991. 
HOPPER, P. J. On some principles of grammaticalization. In: TRAUGOTT, E, HEINE, B. (ed.). Approaches to Grammaticalization I. Amsterdam: John Benjamins, p. 17-35, 1991.

HOPPER, P. J.; TRAUGOTT, E. C. Grammaticalization. 2 ed. Cambridge: Cambridge University Press, 1993.

KURYLOWICZ, J. The evolution of grammatical categories. KURYLOWICZ, Jerzy. Esquisses Linguistiques II. München: Fink, p. 38-54, 1965.

LEHMANN, C. Thoughts on grammaticalization: a programmatic sketch. Vol. 1. Colônia: Arbeiten des Kölner Universalien Projetcts 48, 1982.

LOBATO, L. C. R. Gênero textual na metodologia de pesquisa em gramaticalização. 131 f. Dissertação (Mestrado), Faculdade de Letras, UFMG, Belo Horizonte, 2009.

MATISOFF, J. Areal and Universal Dimensions of Grammaticalization in Lahu. In: TRAUGOTT, E. C.; HEINE, B. (orgs.). Approaches to Grammaticalization. Amsterdan: John Benjamins, p. 331-380, 1991.

LIMA. J. P. de. Sobre a gênese e a evolução do futuro com ir em Português. In: Silva, A. S. da. (org.). Linguagem e Cognição. A perspectiva da linguística cognitiva, Braga: APL/Universidade Católica Portuguesa, Faculdade de Filosofia de Braga, 2001, p. 119196.

MARTELOTTA, M. E.; VOTRE, S. J.; CESÁRIO, M. M. (orgs.). Gramaticalização no português do Brasil: uma abordagem funcional. Rio de Janeiro: Tempo Brasileiro/UFRJ, 1996.

MEILLET, A. L'évolution des formes grammaticales. In: MEILLET, A. Linguistique historique et linguistic générale. Paris: Champion, p.130-148, 1912.

MENON, O. P. da S. Perífrases de gerúndio: o que mudou? Tempo e Linguagem. Araraquara: UNESP, p. 15-40, 2000.

NEVES, M. H. de M. A Gramática Funcional. Campinas: Martins Fontes, 1997.

SAPIR, E. A linguagem: introdução ao estudo da fala. Trad. J. Mattoso Câmara Jr. Rio de Janeiro: Instituto Nacional do livro, 1921/1954. 
SILVA, A. da. A expressão da futuridade no português falado. Araraquara: UNESP, FCL, São Paulo: Cultura Acadêmica Editora, 2002.

VIANNA, H. L. G. A estrutura modal + infinitivo em português: gramaticalização e modalização. 216 f. Dissertação (Mestrado), Faculdade de Letras, UFMG, Belo Horizonte, 2000.

VITRAL, L. T. O papel da frequência na identificação de processos de gramaticalização. Scripta. Revista do Programa de Pós-Graduação em Letras e do Centro de Estudos Luso-afro-brasileiros da PUC/Minas. Belo Horizonte, p.149-177, 2006.

Artigo recebido em: 30.03 .2012

Artigo aprovado em: 01.06.212 